\title{
The Influence of Silica Fume on the Mechanical and Thermal Parameters of Portland Cement Concretes
}

\author{
Jarosław Strzałkowski ${ }^{1}$, Halina Garbalińska ${ }^{1 *}$ \\ 1 Department of Building Physics and Building Materials, Faculty of Civil Engineering and Architecture, West \\ Pomeranian University of Technology Szczecin, al. Piastów 50, 70-311 Szczecin, Poland \\ * Corresponding author's e-mail: Halina.Garbalinska@zut.edu.pl
}

\begin{abstract}
The influence of the silica fume (SF) addition on the basic mechanical and thermal parameters of cement concrete was presented in this paper. Numerous studies show that the specific properties of silica fume allow producing concretes with increased strength and durability properties. However, the results of the authors' own studies demonstrated that under specific circumstances, the SF addition can negatively affect the strength of cement concrete. In this paper, the concretes made from two types of coarse aggregate, 4-8 mm fraction: reference ordinary gravel aggregate (Ref) and broken basalt aggregate (Bas) were tested. Comprehensive tests (microstructural, strength and thermal) were carried out on three formulas: the first one (Ref- 0 ) did not contain any additives or admixtures. Silica fume and superplasticizer were used in the second formula (Ref-8), introduced in the amount of $8 \%$ and $0.75 \%$ of the cement's weight, respectively. The third formula, based on basalt aggregate (Bas-8), also contained silica fume and a superplasticizer, dosed in the same amount as in the second formula. Porosimetric studies showed that the use of silica fume in the Ref- 8 formula resulted in a decrease in the number of pores smaller than $0.15 \mu \mathrm{m}$ in comparison to the Ref- 0 reference concrete without the silica fume. On the other hand, numerous additional pores with diameters ranging from 0.05 to $300 \mu \mathrm{m}$ were found in the Bas- 8 concrete. In turn, optical porosimetry proved that the basalt-based concrete had numerous pores in the range above $70 \mu \mathrm{m}$, which were not observed in the case of the concretes with ordinary pebble aggregate. In the case of the normal concrete, the addition of silica fume resulted in an increase in the compressive strength. However, the basalt-based concrete, due to its much higher porosity, achieved significantly lower strength values. The results showed that the observed changes in porosity, caused by the presence of silica fume, resulted in lower values of thermal conductivity and specific heat of mature composites that it had been added to. This was particularly evident for the basalt-based concrete.
\end{abstract}

Keywords: silica fume, thermal properties, compressive strength, porosity ordinary gravel aggregate, basalt aggregate

\section{INTRODUCTION}

Silica fume, also known as microsilica, is a waste product from the metallurgical industry that occurs in the production of metallic silicon, ferrosilicon and other silicon alloys. It consists of microscopic spherical particles which have a diameter of approximately $0.1 \mu \mathrm{m}$ and a specific surface area of approximately $20 \mathrm{~m}^{2} / \mathrm{g}$. Due to the highly fragmented structure and pozzolanic properties of silica fume, it is a valuable additive for concrete, especially in the era of the development of superplasticizers; which allow the introduction of larger quantities of silica fume into the concrete mix. Addition of microsilica brings tangible ecological and economic profits, related to, among others, the possibility of replacing a significant amount of cement, the production of which has a very significant impact on the natural environment.

The existing examples have also proven to be beneficial in terms of their technical aspects. The literature on this subject contains numerous studies which show that the specific chemical and physical properties of silica fume allow producing the concretes with increased strength and durability. 
The metakaolin-based mortars where metakaolin was replaced by silica fume or colemanite, were examined previously [Uysal et al., 2018]. In the case of the mortars with the silica fume addition, a significant increase in the compressive and flexural strength was observed, as long as microsilica did not exceed $20 \%$ of the mass of metakaolin. At higher concentrations, a lower strength was observed compared to a reference mortar without silica fume. It was also found that the addition of microsilica increased the abrasion resistance of the tested mortars.

Pedro et al. tested concretes with different proportions of silica fume, $0 \%, 5 \%$ and $10 \%$ of the total cement weight, in which natural aggregate was replaced with recycled concrete aggregate [Pedro et al., 2017]. In all groups, there was a several-percent decrease in compressive strength, both with an increase in recycled aggregate content and an increase in the SF content. In addition, the absorption of water by capillary suction and the water absorption of the tested concretes also increased along with the fume content.

Numerous studies on the properties of concrete with recycled aggregates with the addition of silica fume are also being carried out. In a previous study, the possibility of improving the properties of concrete with recycled aggregates through the use of microsilica was discussed [Abd Elhakam et al., 2012]. It was proven that the addition of $10 \%$ of SF in relation to the weight of cement significantly increased the compressive and flexural strength of concrete with $75 \%$ recycled aggregate content. Similar conclusions were found by others [Xie et al., 2018], [Pedro et al., 2018].

The influence of silica fume on the properties of concrete with the addition of waste marble dust was investigated previously [Khodabakhshian et al., 2018]. It was shown that while the addition of marble dust alone has a detrimental effect on the strength of the concrete, the use of a mixture of silica and marble dust can replace up to $30 \%$ of the total weight of cement while maintaining comparable properties to the reference concrete without additives.

A series of tests of concrete with nanosilica, in which the natural quartz aggregate was replaced by glass cullet were described [Skoczylas and Rucińska, a, b, 2018], [Sikora et al., 2016]. In this case, nanosilica was added in the amount of $1 \%$ and $3 \%$ of cement weight. In both instances, an increase in compression strength was observed. Nanosilica, however, caused deterioration in workability and reduced flow of the fresh mixture. The shrinkage during drying was also higher. The information on the use of microsilica in concrete with glass waste is widely discussed in [Mehta and Ashish, 2019].

$\mathrm{Li}$ et al. also investigated the influence of nanosilica [Li et al., 2018]. These authors studied the concretes with the addition of both ordinary microsilica and nanosilica. The authors showed that the addition of nanosilica increases the water demand for mixtures and the necessary amount of superplasticisers in order to obtain the same consistency as in the concrete without silica additives. However, it has been proven that concretes with the same compressive strength as normal nanosilica concrete do not require additional superplasticisers. According to the authors, the concrete mix containing both ordinary microsilica and nanosilica was the most beneficial in terms of strength.

Other additives include magnetite dust, and its influence on the properties of heavy concrete was investigated in [Sikora et al., 2019] and [Horszczaruk and Brzozowski, 2019].

Silica fume can also be used as an additive to improve the properties of concrete based on other waste materials. The concretes with rubber waste [Xie et al., 2019], or waste fibers from coconuts [Khan and Ali, 2019] were tested. In both cases, it was possible to partially mitigate the decrease in the value of mechanical parameters of concrete with waste, owing to the SF addition.

Microsilica is also used in concrete where water contains high levels of bacteria [Siddique et al., 2017]. It was shown that this type of concrete, combined with the silica fume, is characterized by higher mechanical strength than the concrete without bacteria and microsilica. The optimal content of silica dust was determined at the level of $10 \%$ of cement mass. It was also shown that both the content of bacteria and microsilica significantly reduce the water absorption of the tested concretes.

The results of numerous tests carried out on the concretes with the SF addition usually demonstrate the beneficial effect of silica fume on the mechanical parameters of cured composite. However, the application of this additive has proven to lead to an unexpected drop in strength under certain circumstances. On the basis of standard assumptions, it could be assumed, for example, that the simultaneous introduction of a very good 
basalt aggregate into the mixture and additional thickening of the mixture with the use of microsilica must result in a significant increase in the strength of the resulting composite. Meanwhile, such a parallel attempt to improve the strength characteristics resulted in the counter-productive end result. This is related to the specific changes in the microstructure, affecting not only the strength but also other properties of the modified concrete. The paper presents the results of complex studies (microstructural, strength and thermal parameters), indicating the complexity of the problem. The experiment evaluated the effect of the addition of microsilica on the properties of concrete made on two different types of aggregate: ordinary coarse pebble aggregate and heavy crashed basalt aggregate.

\section{MATERIALS AND METHODS}

The research was carried out with the concretes made on the basis of coarse-grained aggregate, pebble-shaped ordinary aggregate (Ref) and crushed basalt aggregate (Bas). Two formulas were tested using an ordinary aggregate of 4-8 $\mathrm{mm}$ fraction, the first of which was made without additives and admixtures (Ref- 0 ). In the second recipe, $8 \%$ microsilica and a superplasticizer $(0.75 \%$ of cement weight $)$ were added to maintain the consistency of the mixture (Ref-8). The formula (Bas-8) also contained microsilica and superplasticizer, and basalt of 4-8 $\mathrm{mm}$ fraction as coarse aggregate.

The same cement, i.e. CEM I-42.5R was used in all the variants. The $\mathrm{W} / \mathrm{C}$ ratio was constant and equal to 0.55 . Similarly, in all mixtures the ratio of sand $0-2 \mathrm{~mm}$ to cement was constant, and equal to 1.2. The composition of individual formulas is presented in Table 1.

For all three types of concrete, 8 samples of $10 \times 10 \times 10 \mathrm{~cm}$ were made for the strength tests and extra 2 samples for the porosimetric tests. The samples were stored for the first 28 days in a high humidity climate chamber. Compressive strength was tested after 7 and 28 days of curing. For each type of concrete and given test date, the mean value of compressive strength $\mathrm{f}_{\mathrm{cm}}$, standard deviation, coefficient of variation and characteristic value of strength $f_{c k}$ were calculated.

The porosity tests of individual composites were also performed, with the measurements using mercury porosimetry as the first step. After three months of curing and drying, the midsections of the cubic samples were cut out. The $0.7 \times 0.7 \times 2.0 \mathrm{~cm}$ samples were prepared from them. The surface tension of mercury was assumed to be $0.48 \mathrm{~N} / \mathrm{m}$ and the contact angle was set to 140 degrees for intrusion. The samples were first subjected to low pressure (up to $0.34 \mathrm{MPa}$ ), then the mercury-filled cells were weighed. Afterwards, they were placed in a pressure chamber and subjected to high pressure (up to approx. $413 \mathrm{MPa}$ ).

Next, the microstructural studies were carried out with the use of optical porosimetry using the RapidAir 457 device. The middle cross-sections with $10 \times 10 \mathrm{~cm}$ side were cut from the cured cubic samples. The samples were finely ground and polished using abrasive powders. Subsequently, the test sample surface was painted black and the pores on the sample surface were filled with white zinc paste. Two test samples for each concrete were tested. The analysed surfaces had a surface area of $8 \times 8 \mathrm{~cm}$. The traverse, from which the readout was made, was $1600 \mathrm{~mm}$ long. Each sample has been tested twice. The second readout was taken after the sample had been turned 90 degrees in the apparatus. The obtained results were merged from both porosity measurements. Figure 1 shows the photos of concrete cross-sections using the SEM technique.

Thermal parameters variability tests were performed with the use of Isomet 2104 device. This method is based on the analysis of heat flow readings at its transient flow. Thermal conductivity coefficients $\lambda$ and volumetric specific heat $\mathrm{cv}$ were read out. The research was carried out after one year of curing of the samples and after their complete drying at the temperature of up to

Table 1. Concrete formulas prepared for testing

\begin{tabular}{|c|c|c|c|c|c|c|c|c|}
\hline \multirow[t]{2}{*}{ Type } & \multirow{2}{*}{ Type of aggregate } & $\begin{array}{c}\text { Coarse } \\
\text { aggregate }\end{array}$ & $\begin{array}{c}\text { Coarse } \\
\text { aggregate }\end{array}$ & Sand & Cement & Water & Silica Fume & $\begin{array}{c}\text { Super- } \\
\text { plasticizer }\end{array}$ \\
\hline & & {$\left[\mathrm{kg} / \mathrm{m}^{3}\right]$} & {$\left[\mathrm{dm}^{3} / \mathrm{m}^{3}\right]$} & {$\left[\mathrm{kg} / \mathrm{m}^{3}\right]$} & {$\left[\mathrm{kg} / \mathrm{m}^{3}\right]$} & {$\left[\mathrm{kg} / \mathrm{m}^{3}\right]$} & [\%] & [\%] \\
\hline Ref-0 & \multirow{2}{*}{$\begin{array}{c}\text { Natural gravel } \\
4-8 \mathrm{~mm}\end{array}$} & 1295.0 & 488.7 & 463.0 & 385.5 & 212.0 & 0.0 & 0.00 \\
\hline Ref-8 & & 1269.0 & 478.8 & 463.0 & 385.5 & 212.0 & 8.0 & 0.75 \\
\hline Bas-8 & Basalt 4-8 mm & 1370.0 & 478.8 & 463.0 & 385.5 & 212.0 & 8.0 & 0.75 \\
\hline
\end{tabular}


a)

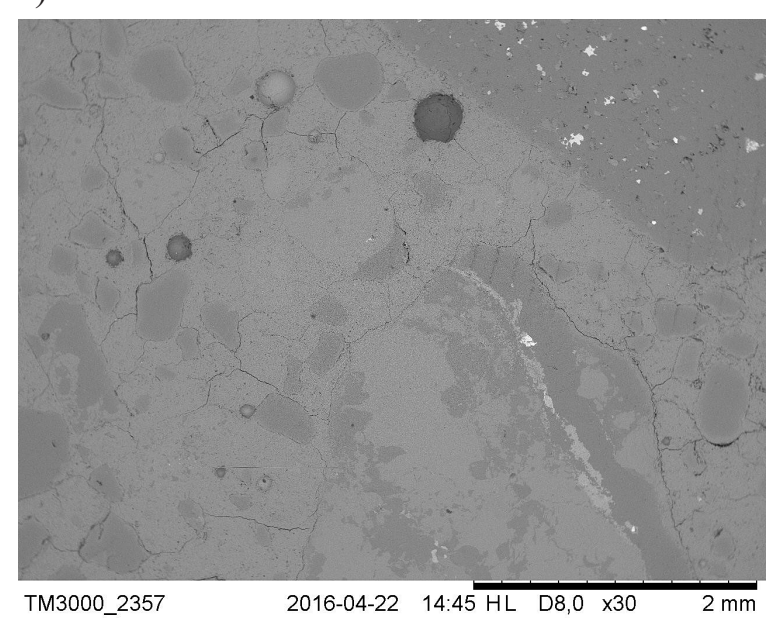

b)

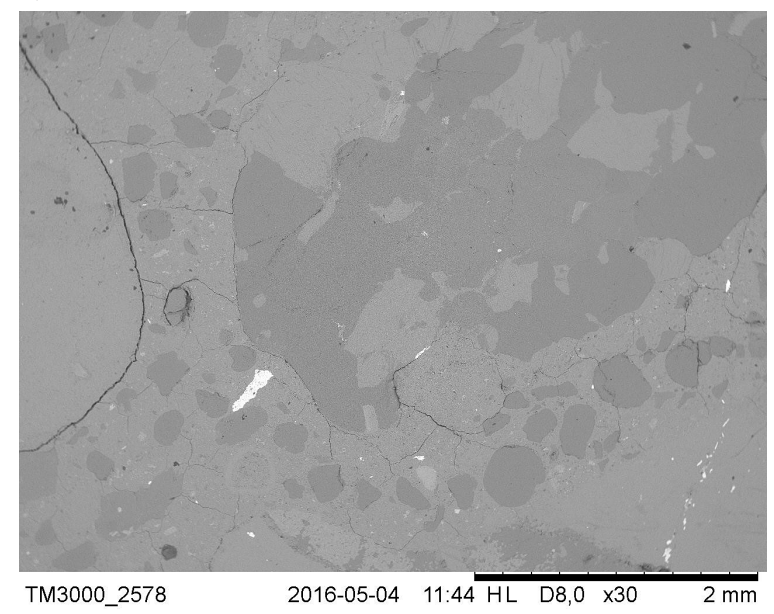

c)

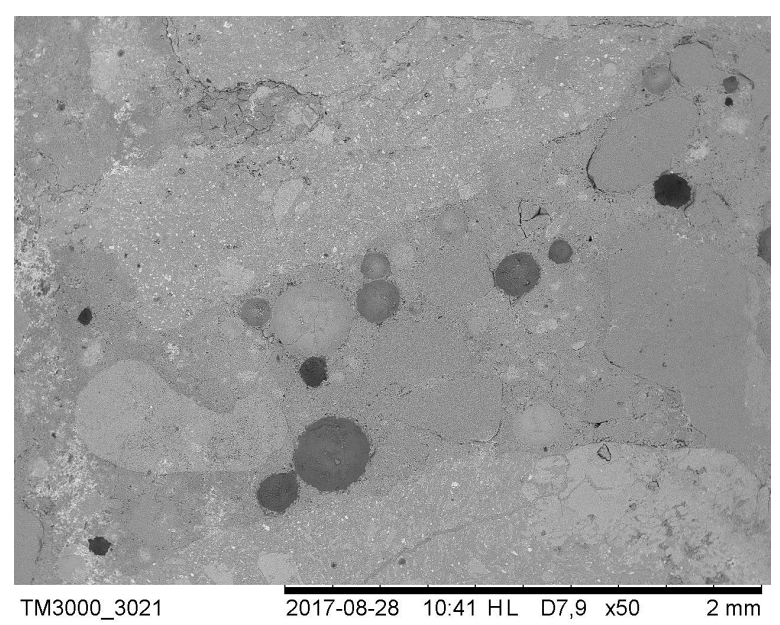

Figure 1. SEM images of samples cross-sections under 30x magnification

$70^{\circ} \mathrm{C}$. The tests were carried out on six samples prepared for each type of concrete. The samples had the dimensions of $4 \times 14 \times 16 \mathrm{~cm}$. The analysed area was the basis of the sample. The average values as well as the standard deviations of the results were determined on the basis of the measurements from all six samples of each concrete.

\section{RESULTS AND DISCUSSION}

Figure 2 shows the log-differential graphs of the porosity structures of individual concretes. The SF addition has resulted in numerous pores with a diameter of less than $0.007 \mu \mathrm{m}$ which are not present in the Ref- 0 reference concrete. The concretes with microsilica are also characterized by a much smaller number of pores in the range of 0.03 to $0.2 \mu \mathrm{m}$. In the case of the Bas- 8 concrete, there are also numerous pores from 0.3 to $4.0 \mu \mathrm{m}$ and from 70 to $300 \mu \mathrm{m}$, which are not found in the concrete based on the reference pebble aggregate.

Figure 3 shows the values of the total specific areas of concretes obtained from mercury porosimetry tests. There is a clear effect of microsilica, which has doubled the specific surface area with reference to the Ref-8 concrete.

Figure 4 shows the log-differential graphs of concrete porosity structures obtained from the optical method. In the tested range from 4 to $4096 \mu \mathrm{m}$, there are clear differences between pebble aggregate and crushed basalt aggregate concrete. Numerous large pores ranging from 30 to $2000 \mu \mathrm{m}$ occurred in the Bas- 8 concrete, in an incomparably larger amount than in the other two tested concretes.

Figure 5 shows the registered specific areas and the spacing factors obtained with optical porosimetry. The optical method is not as sensitive as mercury porosimetry. Nevertheless, the specific surface area $\alpha$ of the Bas- 8 concrete in 


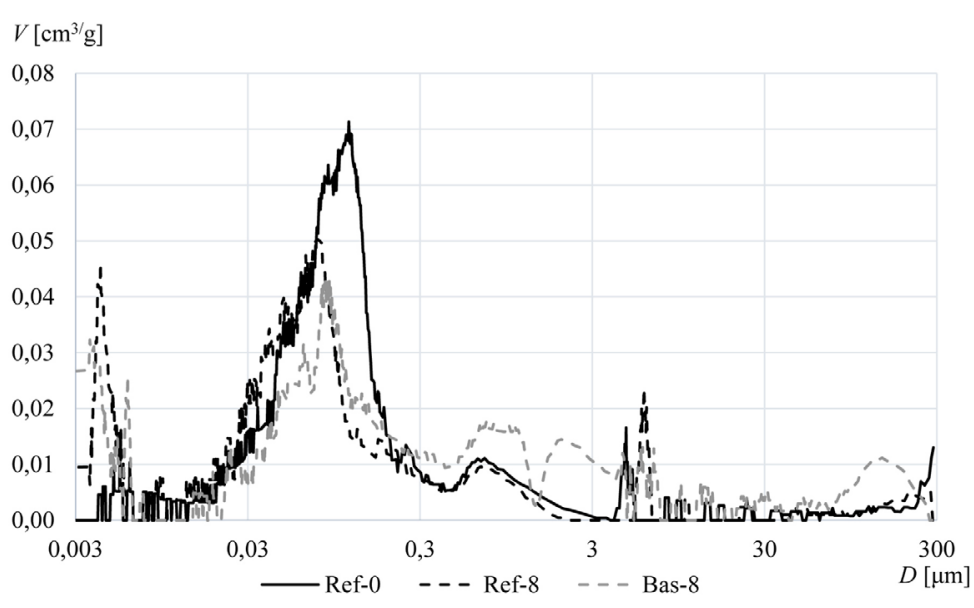

Figure 2. Log-differential graphs of pore structure of the tested concretes, prepared by means of mercury porosimetry

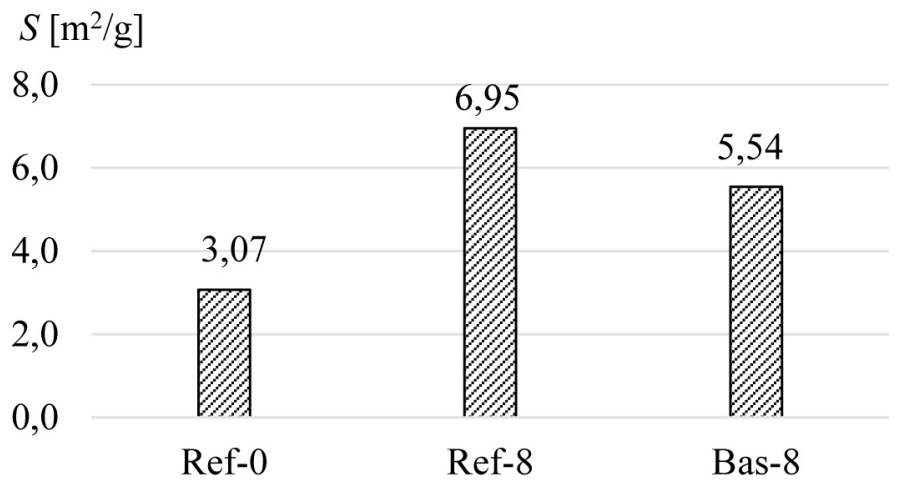

Figure 3. The total surface area of the tested concretes determined by means of mercury porosimetry

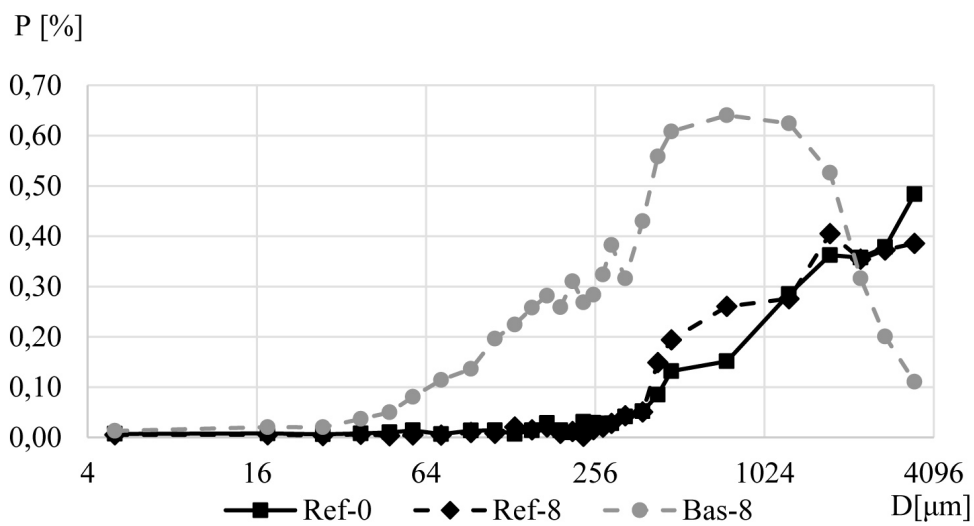

Figure 4. Log-differential graphs of pore structure of the tested concretes, prepared by means of optic porosimetry

relation to the Ref- 0 reference is still increasing. Large differences also exist in the spacing factor L. Due to the presence of numerous large pores in the Bas- 8 concrete, the distribution coefficient is 3-4 times lower than in the Ref- 0 and Ref- 8 concretes based on normal pebble aggregate.
Figure 6 shows the values of average compression strength of concretes after 7 and 28 days of curing. The addition of microsilica in the Ref- 8 concrete resulted in a significant strengthening of concrete compared to ordinary Ref- 0 after both $7(16 \%)$ and $28(12 \%)$ days of curing. In the case 


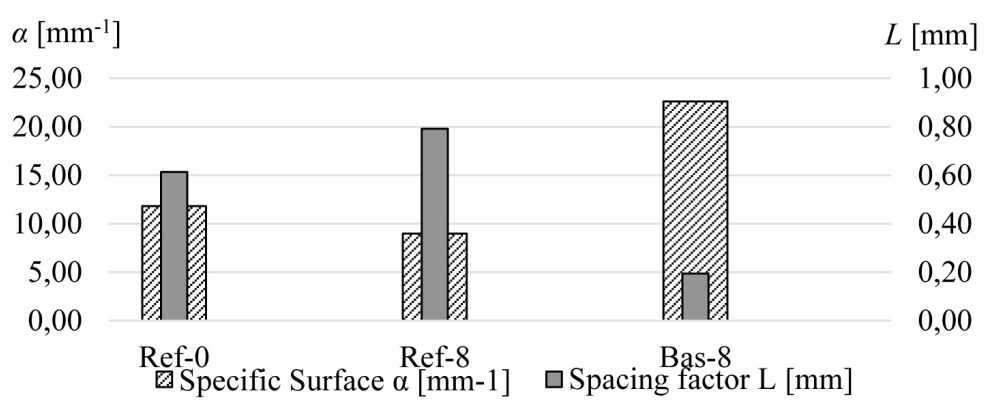

Figure 5. The specific surface and spacing factor of pores of the tested concretes examined by means of optic porosimetry

of basalt based concrete, where numerous additional pores were formed in the range of micro and milli pores, the cement matrix was strongly weakened. This resulted in a significant reduction in strength in relation to the Ref- 0 reference concrete by approx. $32 \%$ after 7 and approx. $18 \%$ after 28 days of curing.

The thermal conductivity coefficients values are given in Figure 7. In Figure 8, the specific volumetric heat and volume density of the tested concretes are given. The individual values refer to the materials dried to a constant mass.

Additional pores in the Ref- 8 concrete caused only a slight change in the thermal conductivity coefficient compared to Ref- 0 . On the other hand, the Bas- 8 concrete based on crushed aggregate is characterized by $20 \%$ lower thermal conductivity than the Ref- 0 concrete and $17.5 \%$ lower than the Ref- 8 concrete. This is caused by a much more aerated cement matrix in the Bas- 8 concrete. The thermal properties of the more porous cement matrix also compensate for the influence of the basalt aggregate itself, which in turn has a higher thermal conductivity than the common aggregate.

The differences in the average volumetric specific heat volume values are small. Despite the more porous structure of the Bas- 8 concrete, its volume density is even higher than that of the reference concrete. This is due to the higher density of basalt aggregate, which also increases the specific heat of the entire material.

\section{CONCLUSIONS}

The paper discusses the results of research on the influence of silica fume on microstructural, strength and thermal properties of concrete made from various coarse aggregates. The results of the experimental studies can be summarised as follows:

- Introduction of microsilica into ordinary concrete based on pebble aggregate resulted in an expected improvement of the mechanical parameters as a result of reduced pore size in the modified composite.

- The use of basalt as a coarse aggregate resulted in numerous additional pores in the cement matrix. In this case, the silica fume did not thicken the cement matrix effectively. The amount of pores in the reference concrete was significantly lower.

- Additional porosity of the Bas-8 concrete resulted in a significant reduction of

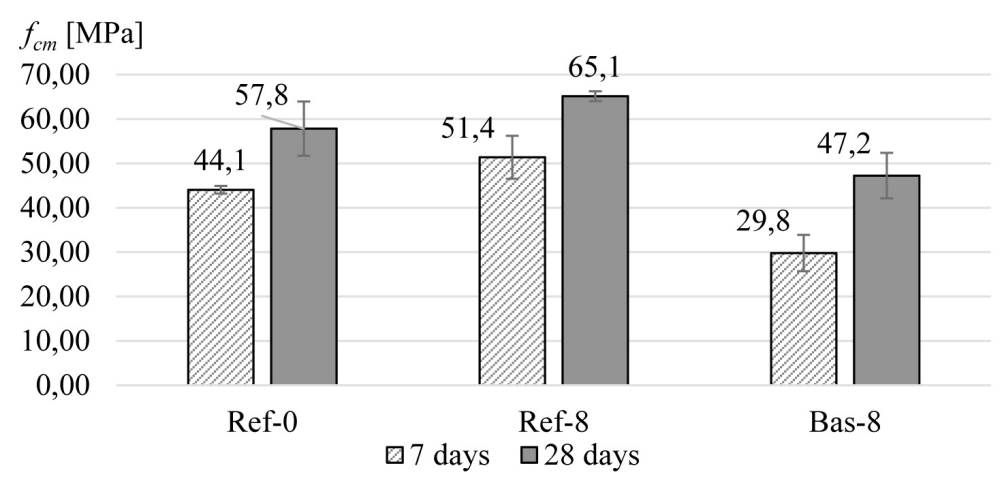

Figure 6. Average compressive strength after 7 and 28 days of composites curing 


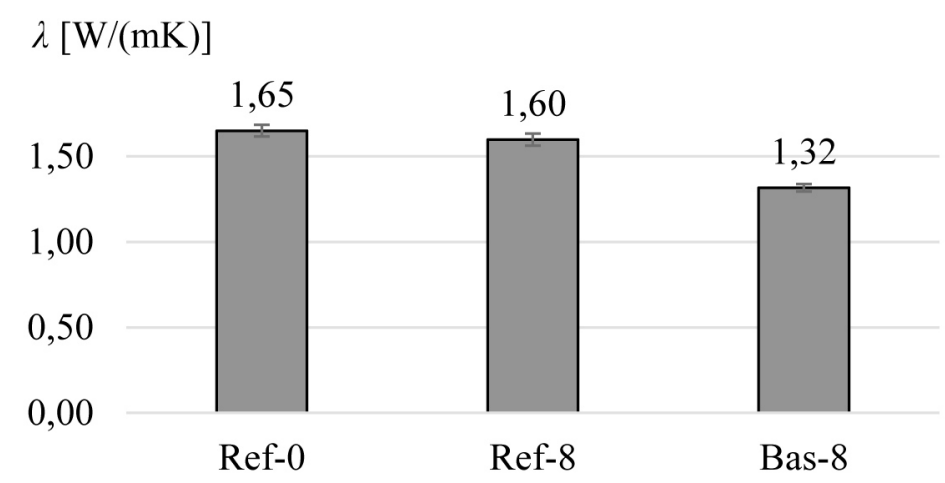

Figure 7. Thermal conductivity coefficients of the tested concretes after oven drying

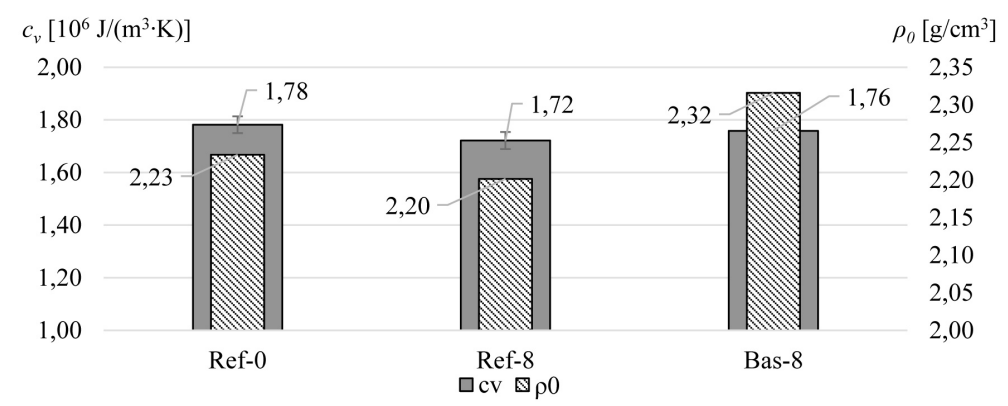

Figure 8. Volumetric specific heat coefficients and volume densities of the tested concretes after oven drying

compression strength in comparison to the reference concretes.

- Aeration of matrix in the Bas-8 concrete resulted in a significant reduction of the thermal conductivity coefficient in comparison to reference concretes.

- Due to the significantly higher density of basalt aggregate in comparison with normal reference aggregate, the specific volumetric heat of the Bas- 8 concrete in dry state has remained practically unchanged in comparison to other concretes, despite the higher porosity of the Bas-8 concrete.

In conclusion, it can be stated that microsilica has improved the strength parameters of the 28-day cured concrete when using normal pebble aggregate, while in the case of the crushed basalt aggregate, it has significantly worsened the strength parameters of the resulting concrete. An attempt to improve the mechanical parameters of concrete by using a very good basalt aggregate and simultaneous addition of microsilica resulted in a composite with a much higher density, but also with a higher porosity. This led to a significant deterioration in the mechanical properties of the material modified in this way. The obtained results indicate the need to be very careful in predicting the effects related to microsilica activity. The results are also dependent on the type of aggregate, usually considered as a neutral factor.

\section{Acknowledgments}

The research of lightweight cement composites was realized as a part of research project no 2014/13/N/ST8/00091 financed by the National Science Centre, Poland.

\section{REFERENCES}

1. Abd Elhakam, A., Mohamed, A.E., Awad, E., 2012. Influence of self-healing, mixing method and adding silica fume on mechanical properties of recycled aggregates concrete. Construction and Building Materials 35, 421-427. https://doi.org/10.1016/j. conbuildmat.2012.04.013

2. Horszczaruk, E., Brzozowski, P., 2019. Investigation of gamma ray shielding efficiency and physicomechanical performances of heavyweight concrete subjected to high temperature. Construction and Building Materials 195, 574-582. https://doi.org/10.1016/j.conbuildmat.2018.09.113

3. Khan, M., Ali, M., 2019. Improvement in concrete behavior with fly ash, silica-fume and coconut fibres. Construction and Building Materials 203, 174-187. https://doi.org/10.1016/j.conbuildmat.2019.01.103 
4. Khodabakhshian, A., Ghalehnovi, M., de Brito, J., Asadi Shamsabadi, E., 2018. Durability performance of structural concrete containing silica fume and marble industry waste powder. Journal of Cleaner Production 170, 42-60. https://doi.org/10.1016/j. jclepro.2017.09.116

5. Li, L.G., Zheng, J.Y., Zhu, J., Kwan, A.K.H., 2018. Combined usage of micro-silica and nano-silica in concrete: SP demand, cementing efficiencies and synergistic effect. Construction and Building Materials 168, 622-632. https://doi.org/10.1016/j. conbuildmat.2018.02.181

6. Mehta, A., Ashish, D.K., 2019. Silica fume and waste glass in cement concrete production: A review. Journal of Building Engineering 100888. https://doi. org/10.1016/j.jobe.2019.100888

7. Pedro, D., de Brito, J., Evangelista, L., 2018. Durability performance of high-performance concrete made with recycled aggregates, fly ash and densified silica fume. Cement and Concrete Composites 93, 63-74. https://doi.org/10.1016/j.cemconcomp.2018.07.002

8. Pedro, D., de Brito, J., Evangelista, L., 2017. Evaluation of high-performance concrete with recycled aggregates: Use of densified silica fume as cement replacement. Construction and Building Materials 147, 803-814. https://doi.org/10.1016/j. conbuildmat.2017.05.007

9. Siddique, R., Jameel, A., Singh, M., BarnatHunek, D., Kunal, Aït-Mokhtar, A., Belarbi, R., Rajor, A., 2017. Effect of bacteria on strength, permeation characteristics and micro-structure of silica fume concrete. Construction and Building Materials 142, 92-100. https://doi.org/10.1016/j. conbuildmat.2017.03.057

10. Sikora, P., Abd Elrahman, M., Horszczaruk, E., Brzozowski, P., Stephan, D., 2019. Incorporation of magnetite powder as a cement additive for improving thermal resistance and gamma-ray shielding properties of cement-based composites. Construction and Building Materials 204, 113-121. https:// doi.org/10.1016/j.conbuildmat.2019.01.161

11. Sikora, P., Augustyniak, A., Cendrowski, K., Horszczaruk, E., Rucińska, T., Nawrotek, P., Mijowska, E., 2016. Characterization of Mechanical and Bactericidal Properties of Cement Mortars Containing Waste Glass Aggregate and Nanomaterials. Materials (Basel) 9. https://doi.org/10.3390/ma9080701

12. Skoczylas, K., Rucińska, T. (a), 2018. Strength and durability of cement mortars containing nanosilica and waste glass fine aggregate. Cem. Wapno Beton 23, 206-215.

13. Skoczylas, K., Rucińska, T. (b), 2018. The effects of waste glass cullets and nanosilica on the long-term properties of cement mortars. E3S Web Conf. 49, 1-9. https://doi.org/10.1051/e3sconf/20184900102

14. Uysal, M., Al-mashhadani, M.M., Aygörmez, Y., Canpolat, O., 2018. Effect of using colemanite waste and silica fume as partial replacement on the performance of metakaolin-based geopolymer mortars. Construction and Building Materials 176, 271-282. https://doi.org/10.1016/j.conbuildmat.2018.05.034

15. Xie, J., Huang, L., Guo, Y., Li, Z., Fang, C., Li, L., Wang, J., 2018. Experimental study on the compressive and flexural behaviour of recycled aggregate concrete modified with silica fume and fibres. Construction and Building Materials 178, 612-623. https://doi.org/10.1016/j.conbuildmat.2018.05.136

16. Xie, J., Li, J., Lu, Z., Li, Z., Fang, C., Huang, L., Li, L., 2019. Combination effects of rubber and silica fume on the fracture behaviour of steel-fibre recycled aggregate concrete. Construction and Building Materials 203, 164-173. https://doi.org/10.1016/j. conbuildmat.2019.01.094 